\title{
A patient has complained about me online. What should I do?
}

\author{
It can be upsetting and unsettling to receive a complaint from a patient online. Abi Rimmer speaks \\ to experts on how best to deal with it
}

\section{Abi Rimmer}

The BMJ

\section{"Maintain patient confidentiality"}

Ellie Mein, medicolegal adviser at the Medical Defence Union, says, "Unfortunately, online complaints are becoming increasingly common and can be upsetting. Feedback can range from mild dissatisfaction through to abusive comments, so how you approach it will depend on the nature of the complaint.

"Comments on sites such as NHS Choices that amount to a straightforward complaint can be responded to online. Thank the patient for their comments, apologise that they are not happy with their treatment (without giving any details of their care), and invite them to get in touch directly to discuss any concerns. This approach is in line with the NHS complaints procedure, which emphasises the need to be open and honest with complainants and to learn from complaints.

"Remember that any comments made in an online response should maintain patient confidentiality and your professionalism.

"If you believe the comments have the potential to damage your reputation, you could ask the moderator or host of the page to remove them, although this may not always succeed.

"These approaches carry risks and it's sometimes better to ignore a comment. Your medical defence organisation can advise you how best to proceed.

"If you can identify the patient who made the comment, you could consider inviting them to discuss their concerns face to face. If the comments were inappropriate, you can follow up this discussion with a warning letter about their behaviour, but be aware this may provoke a further online response."

\section{"Always remain professional"}

Alison Whiting, standards policy officer at the General Medical Council, says, "It can be frustrating and upsetting to see criticisms about yourself on social media-especially when the information is inaccurate or misleading.

"The rise of rating platforms-though welcome in giving patients another avenue for feedback-has made this problem more common for doctors. We know doctors sometimes feel that the commentary is unfair and would like to respond. But as a public tit-for-tat could prolong or inflame a conflict, our advice is that you should usually avoid doing so.
"There may be occasions where it might be appropriate to give a general response, describing normal practice. For example, this could be the case if social media discussions might cause patients to be concerned about your practice or that of a health service you are associated with.

"But you must ensure that you don't reveal in the public domain - directly or by omission or inference-any information about a patient that you have learnt in confidence. Patients may avoid seeking medical help, or may under-report symptoms, if they think that their personal information will be disclosed by doctors without consent, or without the chance to have some control over the timing or amount of information shared.

"If you decide to comment, you should generally limit your public response to an explanation of your legal and professional duty of confidentiality. And, whatever the provocation, always remain professional and polite; an intemperate response could undermine the public's confidence in the profession.

"We encourage you to seek advice from your defence body or a solicitor on how to respond and, if appropriate, whether any legal redress may be available to you."

\section{"You are not alone"}

Lucy Powell, elected member of the Association of Anaesthetists Trainee Committee, says, "Reading negative comments may be extremely upsetting and it's important to acknowledge this. Understandably, you might feel defensive, anxious, or stressed. Try and detach emotion from fact and don't be tempted to make a knee jerk response.

"Complaints are a fact of the medical professional's life. Whether founded or not, it's useful to recognise that they will unfortunately be a problem for many of us. You are not, and should not feel, alone.

"Seek counsel from trusted colleagues. They may have faced a complaint personally and be able to offer advice or they may simply offer a listening ear.

"Reflect. Try to keep to the facts rather than let emotions cloud your judgment. This may help you to understand why the complaint came about. Be honest; you may have made a mistake or done something wrong. This doesn't have to end your career. We all make mistakes and it's how we learn from them that matters. 
"Try and write down what you remember-this will be useful when contacting your defence union and if you have to write a formal response. Consider including a brief entry in your portfolio to say you've received a complaint and taken the opportunity to reflect, keeping a more detailed anonymised account for private records.

"Contact your defence union, particularly before you respond. They will advise on the proper procedure and tell you what to do, including who to contact at work.

"Complaints can be bitter pills but keeping calm, sharing experiences with supportive colleagues, and following the advice of professionals in a defence union can make them easier to swallow."

\section{"Tone is important"}

Pallavi Bradshaw, medicolegal lead for risk prevention at Medical Protection, says, "When dealing with online complaints, you should use it as an opportunity to demonstrate your professionalism through empathy and a desire to improve the care you provide to your patients. A good response will reflect well on you and your practice or hospital, which will help counterbalance the negative remarks that have been made. A response which is calm and measured is powerful and can diffuse a potentially emotive situation quickly. Thank the patient for their comments, acknowledge the specific concerns they have raised, and apologise if appropriate.

"GMC guidance says that you should usually limit your public response to an explanation of your legal and professional duty of confidentiality. ${ }^{1}$ However, it recognises that online discussions might cause patients to be concerned about your practice. In such cases, the GMC says it may be appropriate to give general information about your normal practice. The guidance stresses that you must be careful not to reveal any information about the patient or their treatment.

"What you say and how you say it is as important, if not more so, than the comments that patients have made about you. Disputes between patients and doctors conducted in public can prolong or intensify the conflict. A professional response will come across well to any others who may read the comments; it's the best way to try to resolve the patient's concerns as swiftly as possible and maintain public confidence in the profession. "Lastly, you may seek further advice from your medical defence organisation on responding to a specific online complaint."

1. General Medical Council. Responding to criticism in the media. www.gmc-uk.org/ethicalguidance/ethical-guidance-for-doctors/confidentiality-responding-to-criticism-in-the-media/ responding-to-criticism-in-the-media.

Published by the BMJ Publishing Group Limited. For permission to use (where not already granted under a licence) please go to http://group.bmj.com/group/rights-licensing/ permissions 